MATEC Web of Conferences 6, 06002 (2013)

DOI: $10.1051 /$ matecconf/20130606002

(C) Owned by the authors, published by EDP Sciences, 2013

\title{
Experimental assessment of concrete damage due to exposure to high temperature and efficacy of the repair system
}

\author{
Y.K. Guruprasad and A. Ramaswamy \\ Indian Institute of Science, Bangalore, India
}

\begin{abstract}
The present study experimentally evaluates the performance of control (standard cylinder specimen), damaged (mechanical loading after thermal exposure) and repaired / retrofitted normal plain concrete cylinders using different repair schemes such as on use of FRP wraps, Geo-polymers, etc., to restore the capacity of damaged structural concrete elements. The control-companion specimen in the series provides the reference frame against which both, specimen damage levels were quantified and the benefits of a specimen repaired subsequent to damage were assessed.
\end{abstract}

\section{INTRODUCTION}

Damage to concrete due to extreme loads, such as fire, is important in the safety assessment of structures. Many studies have examined different aspects of this problem such as loss of mechanical properties of concrete when exposed to high temperature $[2,3,5]$ and enhancement of mechanical properties of concrete through repair measures $[1,4]$. The present study examines the combined problem of damage to plain concrete due to "fire": thermal loading and the possibilities of repairing such a damaged structure.

This study looks at the behavior of concrete cylinders of $25 \mathrm{MPa}$ and $35 \mathrm{MPa}$ cylinder compressive strengths damaged under "fire" (exposure to high temperature in an electric furnace), cooled and thereafter wrapped with CFRP and subjected to monotonic compression loading. Control concrete cylinders of $25 \mathrm{MPa}$ and $35 \mathrm{MPa}$ cylinder compressive strengths (not damaged with fire and without CFRP) were first tested to access their stress strain behavior in monotonic compression. Another set of concrete cylinders of the same cylinder strength as specified above were subjected to "fire" damage for temperatures of $715 \mathrm{deg} C$ for a duration of 2 to 4 hours, $550 \mathrm{deg} C$ for a duration of 4 hours and $425 \mathrm{deg}$ $\mathrm{C}$ for a duration of 4 hours in a furnace and allowed to cool in air till they attained room temperature. One set of the "fire" damaged cylinders, which had cooled and attained room temperature were subjected to monotonic compression loading without CFRP wrap to assess the ultimate compressive strength at failure and obtain the stress strain response. Another set of fire damaged cylinders which had cooled and had attained room temperature were wrapped with CFRP and was subjected to monotonic compression loading to assess the increase in the compressive strength at failure and their stress strain response after repair.

While damage under mechanical loading may be induced under monotonic loading up to failure, a second form of damage under mechanical loads may be initiated and progress to failure due to relatively smaller loads applied cyclically. These cyclic loads may manifest themselves due to machine vibrations as in the case of concrete employed in foundations as or due to earthquake or wind gust loads in tall building and long span bridge structures. These loads may be either constant amplitude cyclic loads (as in machine foundations) or variable amplitude cyclic loads as in earthquake or wind

This is an Open Access article distributed under the terms of the Creative Commons Attribution License 2.0, which permits unrestricted use, distribution, and reproduction in any medium, provided the original work is properly cited. 
Table 1. Results from Monotonic uniaxial load tests on Concrete Cylinders exposed to different combinations of temperature and duration with and without CFRP repair.

\begin{tabular}{|c|c|c|}
\hline Classification of Concrete Cylinders & $\begin{array}{c}\text { Ultimate Uni-axial } \\
\text { Ultimate Uni-axial } \\
\text { compressive strength } \\
\text { at failure(MPa) }\end{array}$ & $\begin{array}{c}\text { compressive strength } \\
\text { at failure(MPa) } \\
\text { With one layer } \\
\text { of CFRP }\end{array}$ \\
\hline Control concrete cylinder 25MPa & $25.5 \mathrm{MPa}$ & $35 \mathrm{MPa}$ \\
\hline Concrete cylinder 25 MPa exposed to 425 deg C for 4 hrs & $19.3 \mathrm{MPa}$ & $31.1 \mathrm{MPa}$ \\
\hline Concrete cylinder 25 MPa exposed to 550 deg C for 4 hrs & $12.4 \mathrm{MPa}$ & $21.8 \mathrm{MPa}$ \\
\hline Concrete cylinder 25 MPa exposed to 715 deg C for 2 hrs & $6 \mathrm{MPa}$ & $14.6 \mathrm{MPa}$ \\
\hline Concrete cylinder 25 MPa exposed to 715 deg C for 4 hrs & $4.6 \mathrm{MPa}$ & $11.4 \mathrm{MPa}$ \\
\hline Control concrete cylinder 35 MPa & $35 \mathrm{MPa}$ & $45 \mathrm{MPa}$ \\
\hline Concrete cylinder 35 MPa exposed to 550 deg C for 4 hrs & $12.0 \mathrm{MPa}$ & $25 \mathrm{MPa}$ \\
\hline Concrete cylinder 35 MPa exposed to 715 deg C for 2 hrs & $7.0 \mathrm{MPa}$ & $14.9 \mathrm{MPa}$ \\
\hline Concrete cylinder 35 MPa exposed to 715 deg C for 4 hrs & $4.9 \mathrm{MPa}$ & $9.7 \mathrm{MPa}$ \\
\hline
\end{tabular}

induced vibrations. The present study also examined the reduction in capacity under cyclic loading due to degradation induced by exposure to high temperature. CFRP wrap based repair was also employed to assess restoration in capacity.

The CFRP used was in a fabric form with $0-90^{\circ}$ orientation of the fibres. One layer of CFRP was adhered to the concrete cylinder surface with help of a epoxy resin adhesive. The testing of the "fire" damaged CFRP wrapped concrete cylinders were done only after the epoxy resin adhesive had dried completely under room temperature. Properties of CFRP and the epoxy resin after 7 days of curing (drying) at $25^{\circ} \mathrm{C}$ room temperature is given in Table 1 respectively. The mode of failure of the cylinders which were damaged under "fire" without CFRP wrap and wrapped with CFRP was studied. The strains on the concrete surface of the cylinders and on the CFRP were recorded with the help of electrical strain gauges which were adhered to the surfaces of concrete (internal - strain gauge adhered to concrete surface enclosed inside the CFRP) and CFRP (on the surface of the CFRP).

\section{EXPERIMENTAL PROGRAM}

Concrete cylinders of $25 \mathrm{MPa}$ and $35 \mathrm{MPa}$ cylinder compressive strength were cured in water for 28 days were tested. Control Concrete cylinders (not damaged with "fire" and without CFRP) of $25 \mathrm{MPa}$ and $35 \mathrm{MPa}$ cylinder compressive strengths were tested under monotonic compression loading to obtain their ultimate compressive strength $\left(\sigma_{u}\right.$ in $\left.\mathrm{MPa}\right)$ at failure and their stress strain behavior in monotonic compression. Microstructure studies have also been undertaken to identify nature of damage.

\subsection{Concrete cylinders: Monotonic uniaxial compressive loading}

Concrete cylinders of cylinder compressive strengths $25 \mathrm{MPa}$ and $35 \mathrm{MPa}$, that were damaged in "fire", were subjected to monotonic compression loading after the cylinders were cooled in air and had attained room temperature. The series comprised of concrete cylinders that were exposed to temperatures ranging from 425 degree Celsius to 715 degree Celsius for duration of 2 to 4 hours in a furnace that had a thermocouple and temperature indicator. Ultimate compressive strengths at failure for control concrete cylinders and "fire" damaged concrete cylinders without CFRP wrap subjected to monotonic loading is shown in Table 1.

It was observed that the concrete cylinders that were exposed to higher temperatures of (550 degree Celsius and beyond) had excessive cracking due to loss of both free and bound water and due to thermal 
IWCS 2013

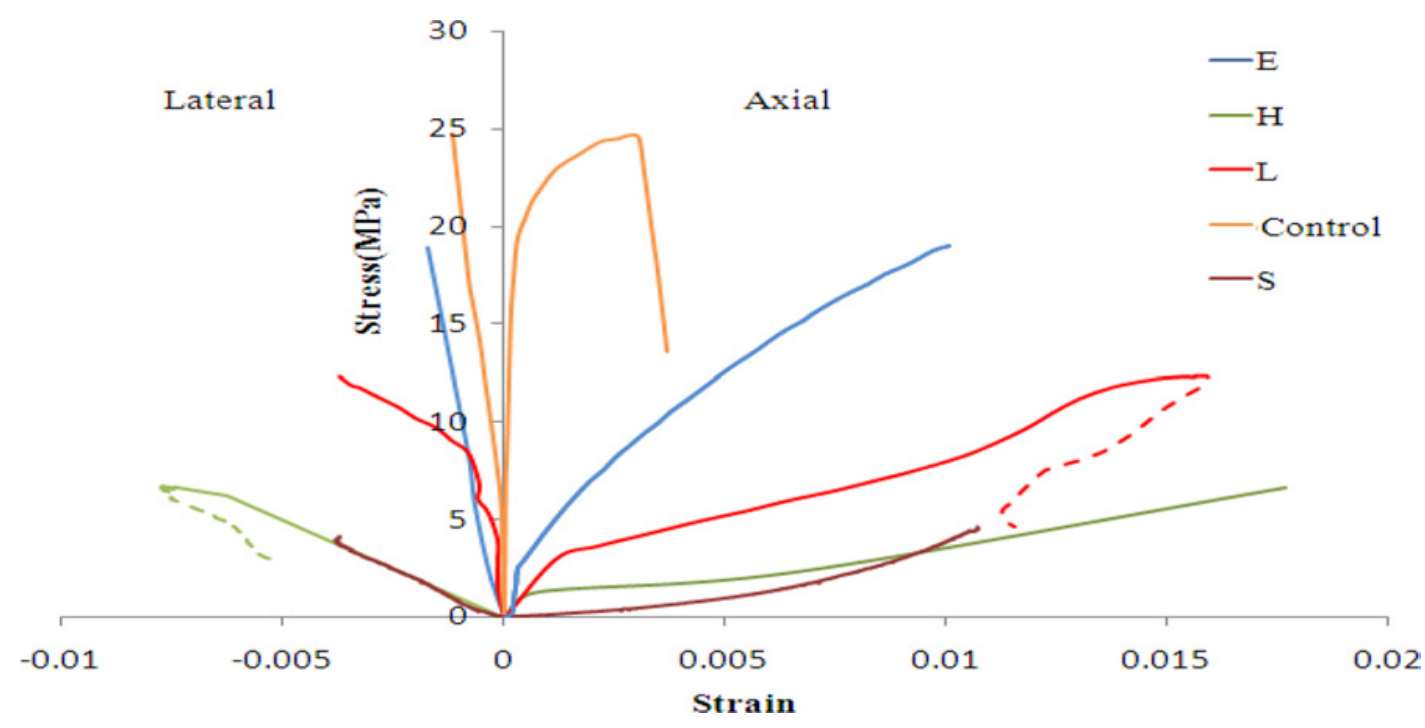

Figure 1. Stress strain response of concrete cylinders of cylinder compressive strengths $25 \mathrm{MPa}$ damaged under fire and subjected to monotonic compressive loading without CFRP wrap.S - 715 deg C - 4 hrs, H - 715 deg C - 4 hrs, L - $550 \operatorname{deg}$ C - 4 hrs, E - $425 \operatorname{deg}$ C - 4 hrs.

expansion and these cylinders also had a slight pinkish coloration when compared to concrete cylinders which were exposed to only $425 \operatorname{deg} \mathrm{C}$ for 4 hours.

During the testing, it was observed that the "fire" damaged cylinders without CFRP wrap failed at a lower load at larger strains when compared to the control cylinders. The failure of unrepaired fire damaged concrete cylinders in compression was gradual and slow giving sufficient warning before failure such as crackling sound of concrete cracking and with noticeable concrete bulging and spalling at mid height of the cylinders. In contrast the control cylinders subjected to monotonic compression behaved in a brittle manner and failed suddenly during failure without giving any warning of failure. The stress strain response of concrete cylinders of cylinder compressive strengths $25 \mathrm{MPa}$ and $35 \mathrm{MP}$ damaged under "fire" for the above said temperatures and subjected to monotonic compressive loading without CFRP wrap is shown in Figure 1.

Another set of concrete cylinders of cylinder compressive strengths $25 \mathrm{MPa}$ and $35 \mathrm{MPa}$, were damaged in "fire" as earlier but were wrapped with CFRP after the "fire" damaged cylinders were cooled in air until the cylinders had attained room temperature and thereafter these cylinders were subjected to monotonic compression loading.

These concrete cylinders, which were damaged in "fire" and wrapped with CFRP after cooling, exposed to temperatures ranging from 425 degree Celsius to 715 degree Celsius for duration of 2 to 4 hours in a furnace that had a thermocouple and temperature indicator. Ultimate compressive strengths at failure for "fire" damaged concrete cylinders wrapped with CFRP after "fire" damage subjected to monotonic compression loading is shown in Table 2.

During the testing, it was observed that the fire-damaged cylinders with CFRP wrap failed at a higher load when compared to the fire damaged concrete cylinders without CFRP wrap. The failure of the "fire" damaged cylinders wrapped with CFRP in compression looked more ductile and these cylinders failed by giving sufficient warning before failure such as crackling sound of concrete and opening of the CFRP, which gradually tore vertically with increase in the axial load. A comparison of strength of the cylinder without and with CFRP having identical temperature and exposure is shown in Table 1. 


\section{MATEC Web of Conferences}

Table 2. Properties of CFRP and the epoxy resin after 7 days of curing (drying).

\begin{tabular}{|l|l|l|}
\hline \multicolumn{2}{|c|}{ Properties of CFRP } & Properties of Epoxy \\
\hline Tensile Strength & $600 \mathrm{MPa}$ & $350-400 \mathrm{Kg} / \mathrm{cm}^{2}$ \\
\hline Compressive Strength & $420 \mathrm{MPa}$ & $800-1200 \mathrm{Kg} / \mathrm{cm}^{2}$ \\
\hline Young's Modulus & $50 \mathrm{GPa}$ & $2000-2200 \mathrm{Kg} / \mathrm{cm}^{2}$ \\
\hline
\end{tabular}

\subsection{Concrete cylinders: Cyclic uniaxial compressive loading}

The present study considered only the constant amplitude loading scenario. Control reference specimen subject to cyclic loads ( $60 \%$ of compressive strength applied as mean compression and $+/-30 \%$ of the compressive strength applied cyclically about this mean compressive stress) till the specimen failed. Thus the constant amplitude undamaged cycles of load served as a reference to assess damage extent in other loading scenarios of cyclic loading. In addition to assessing damage due to mechanical loading and the benefits of repairing these plain concrete cylinder specimen with CFRP layers, a second form of damage induced by exposure to high temperatures over extended periods, such as due to fire damage was considered in the test program. Plain concrete cylinder specimens were placed in a high temperature electrical oven / furnace at temperatures ranging from 450 degree Celsius to 715 degree Celsius for durations ranging from two to four hours. The specimen were thereafter removed from the furnace and cooled for over a day prior to testing them under uni-axial compressive loads. While one set of such cylinders tested under uni-axial loads provided information on the extent of damage caused by thermal loads, a second set of these cylinders were wrapped with one layer of CFRP and tested to assess the likely strength enhancement accrued from the repair process. Thus this set of tests comprised of a) control plain concrete cylinder specimen from the two strength mixes exposed to ambient temperature conditions loaded uni-axially up to failure, b) plain concrete cylinders from the two strength mixes exposed to 450 degree $\mathrm{C}$ for $2 \& 4$ hours, 550 degree $\mathrm{C}$ for 2 and 4 hours, 715 degree $\mathrm{C}$ for 2 and 4 hours that were then cooled and tested monotonically under uni-axial compression to failure, c) a companion series as in b) but with one layer of CFRP wrap pasted on the lateral surface of the cylinders and then tested monotonically under uni-axial compression up to failure.

Concrete cylinders which were not wrapped with CFRP and exposed to temperature of 425 deg C for a duration of 4 hours in a furnace, cooled and there after subjected to cyclic loading in compression $\left(39 \% \sigma_{u} \pm 15 \% \sigma_{u}\right)$, failed at 18,700 cycles. Companion cylinders exposed to $425 \mathrm{deg} \mathrm{C}$ for a duration of 4 hours in a furnace, cooled and thereafter wrapped with one layer of CFRP and subjected to cyclic loading in compression $\left(60 \% \sigma_{u} \pm 27 \% \sigma_{u}\right)$, failed at 25,560 cycles. Thus, CFRP wrap is seen to considerably enhance the strength capacity of concrete under cyclic loading, when used to repair specimen damaged due to thermal exposure. $\sigma_{u}$ is the peak compressive strength under monotonic loading.

\subsection{Geo-polymer based thermal insulation}

A set of concrete cylinders of $25 \mathrm{MPa}$ compressive strength $(150 \mathrm{~mm}$ in diameter and $300 \mathrm{~mm}$ in height were plastered with geo-polymer mortar with $31 \mathrm{~mm}$ thickness and exposed to temperatures $715 \mathrm{deg} \mathrm{C}$ for $4 \mathrm{hrs}$ and $550 \mathrm{deg} \mathrm{C}$ for $4 \mathrm{hrs}$ to study the degree of thermal insulation provided by the mortar.

Two mixes of Geo-polymer mortar were prepared. In the first mix fly ash to fine aggregate to sodium silicate (0.5 Molar) to sodium hydroxide (10 molar) were proportioned as 1: 1.22:0.3374:0.1712. In the second mix the proportion and constituents were the same, except that the sodium hydroxide was a commercial grade product. With mix 1 the strength increase with a $30 \mathrm{~mm}$ coating was small from 4.6 MPa to 6.01 MPa when exposed to $715 \mathrm{deg} \mathrm{C}$ temperature for 2 hours. The tests indicated that the mechanical strength increased marginally in the first case but the increase was substantial with mix 2 because of the thermal coating, offering hope of evolving a suitable thermal insulator. The strength gain 
IWCS 2013

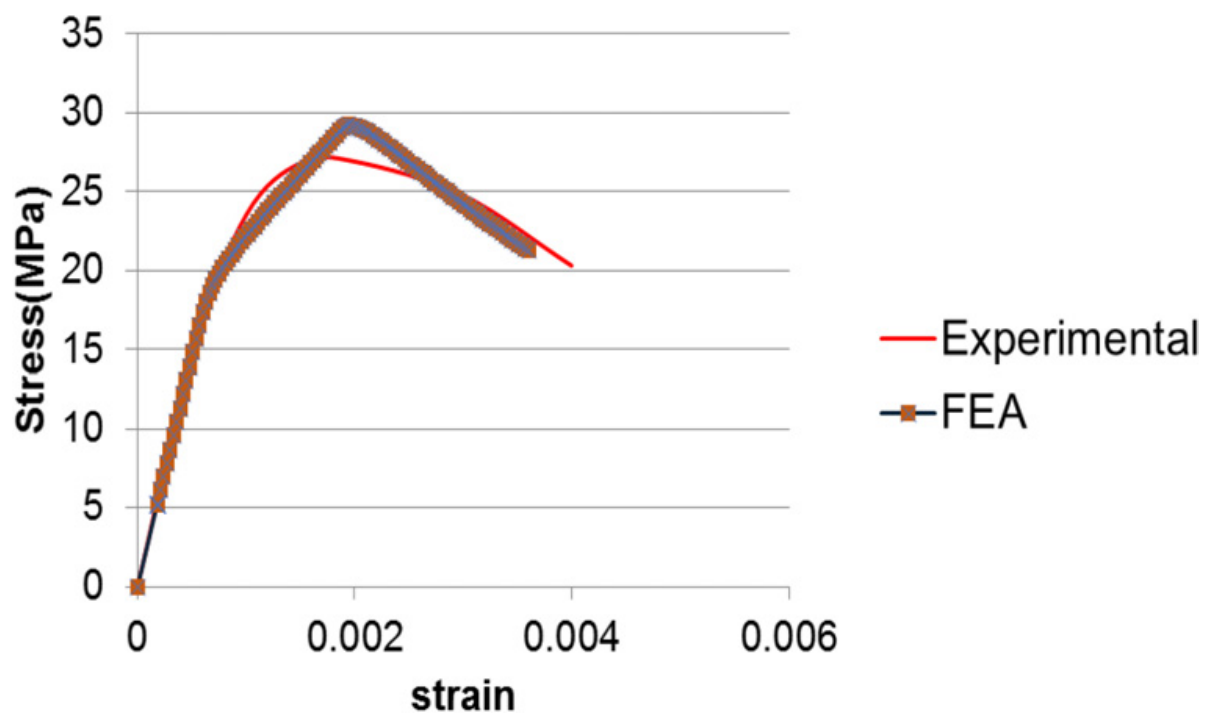

Figure 2. Comparison of Experimental and Numerical Simulation of Control Cylinder response under monotonic Uniaxial Compressive loads.

for specimen exposed to $550 \mathrm{deg} \mathrm{C}$ for 4 hours when covered with $30 \mathrm{~mm}$ covering of geo-polymer mix 2 was from $12.4 \mathrm{MPa}$ to $18.27 \mathrm{MPa}$.

\section{NUMERICAL MODELLING}

Finite element software ABAQUS is used to simulate the experimental results. While the concrete is modelled using solid elements, the CFRP is being modelled as a shell, with the interface with concrete represented using normal and tractive forces representing the adhesive bond. A refined mesh representation with the CFRP as a solid element is also being employed to study the effectiveness of the simulation. The CFRP properties being used in this study are as in Table 2. Figure 2 shows the ABAQUS prediction of the control cylinder (without thermal damage or CFRP) under monotonic loading.

\section{CONCLUSION}

The test program indicates that damage to concrete is enhanced at temperatures above 550 degree Celsius. The duration of the thermal exposure (at a given temperature) is also seen to effect the overall damage induced in the concrete.

CFRP based repair of damaged cylinder specimen is found to significantly enhance the strength capacity of concrete showing that the repair was effective, and also this showed that the "fire" damaged concrete cylinders which had cracked excessive was well confined by the CFRP under monotonic compressive loading.

\section{References}

[1] Guoqiang Li, Dinesh Maricherla, Kumar Singh, Su-Seng Pang, Manu John. (2006), 'Effect of fiber orientation on the structural behavior of FRP wrapped concrete cylinders', Journal of Composite Structures, 74, pp. 475-483.

[2] Jaesung Lee, Yunping Xi, and Kaspar Willam. (2008), 'Properties of Concrete after High Temperature Heating and Cooling', Journal of ACI Materials, V.105, No.4, pp. 334 - 341. 


\section{MATEC Web of Conferences}

[3] M. Takeuchi, M. Hiramoto, N. Kumagai, N. Yamazaki, A. Kodaira and Sugiyama K. (1993), 'Material properties of concrete and steel bars at elevated temperatures', SMirt - 12 /K. Kussmaul(editor)(CElsevier Science Publishers B.V., pp. 133 - 138.

[4] Roslan Ahmad, Zaidi Mohd Ripin , Pasricha M.S. (2001), 'Compressive Properties of Carbon Fibre Reinforced Plastic (CFRP) at Low Strain Rate', Pertanika J. Sci. \& Techno, Supplement 9(2), pp. $219-227$.

[5] Ulrich Schneider. (1988), 'Concrete at High Temperatures - A General Review', Fire Safety Journal, 13, pp. $55-68$. 